2

\section{In An Airship Built For Two}

Lyric by

PARKES B. CHURCHILL

Music by

RAY HIBBELFR

Moderato

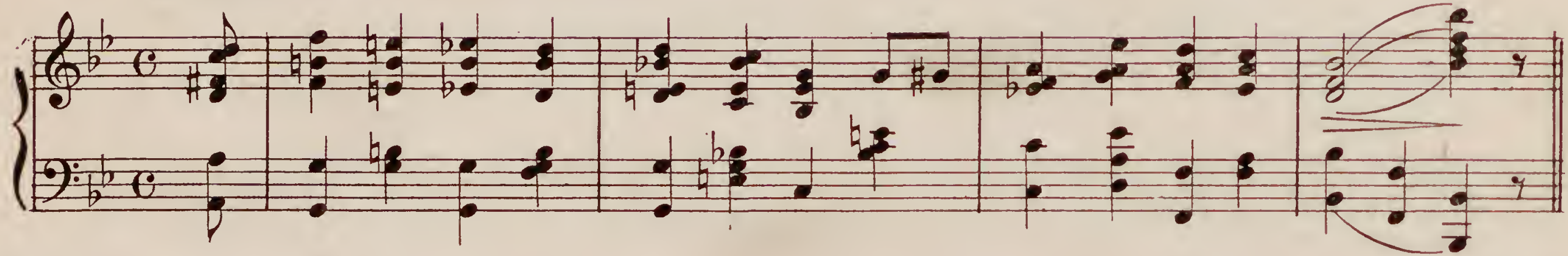

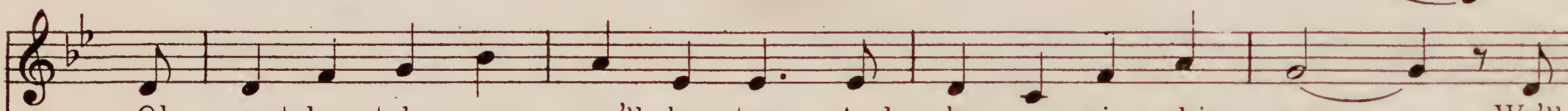

Oh sweet-heartdo say you'll be true And be my air-ship queen__ We'll

You say the word then like a bird Up in the air we'll start_on

in the air while fly - ing there In our lit - tle aer-o - plane.

py we'll be o'er land and sea In an air-ship built for two.

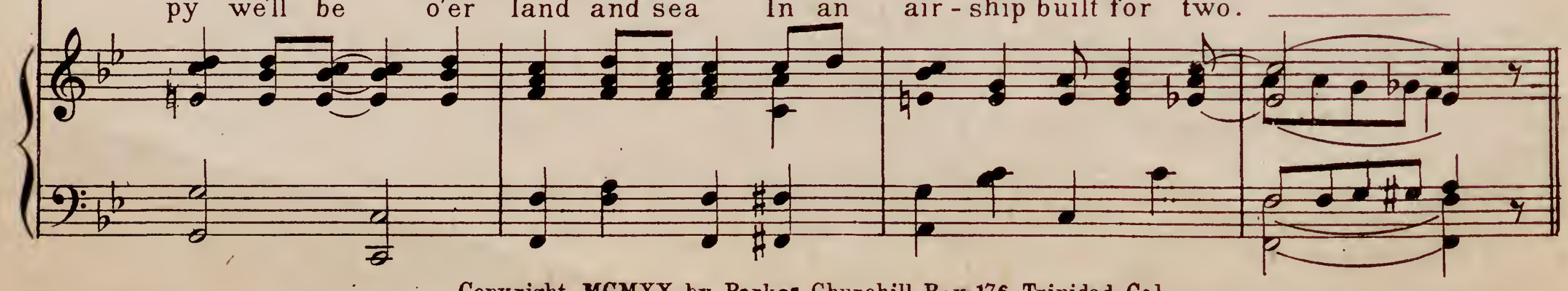




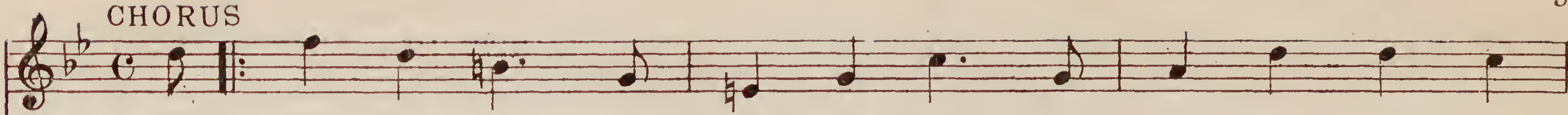
We'll take a trip in our air-ship It's just the place to

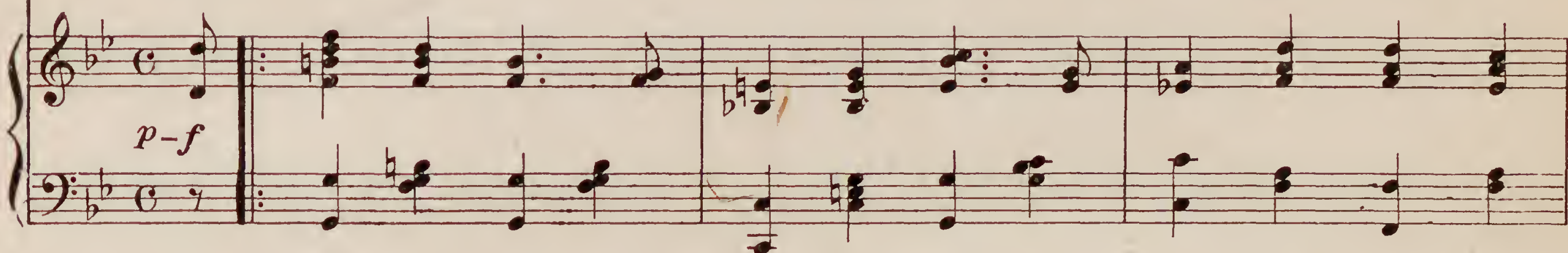

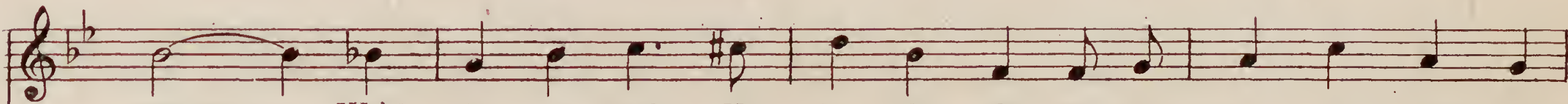
spoon W We'li fly on high Up to the sky on our lit - tle hon - ey-

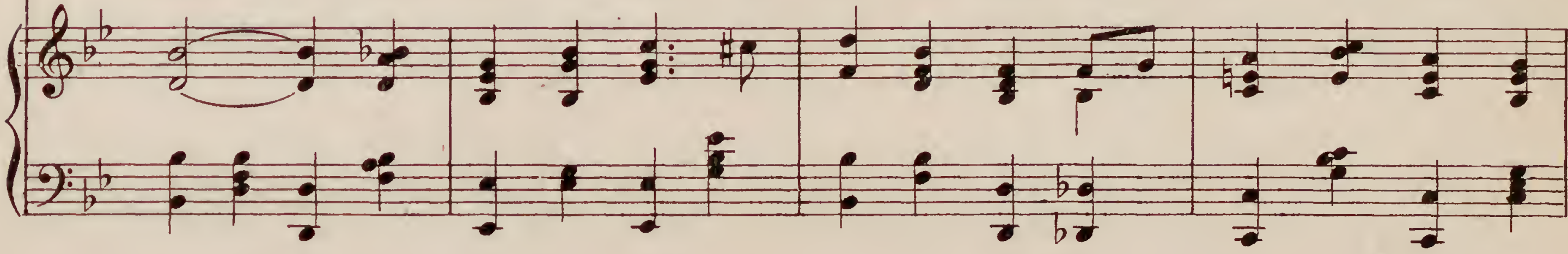

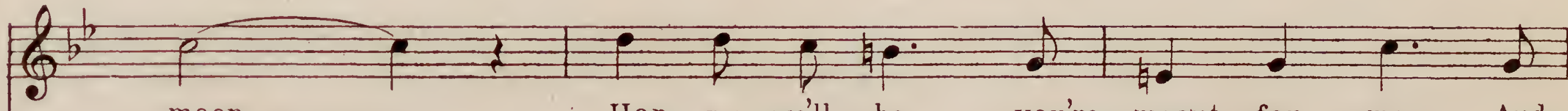
(n)

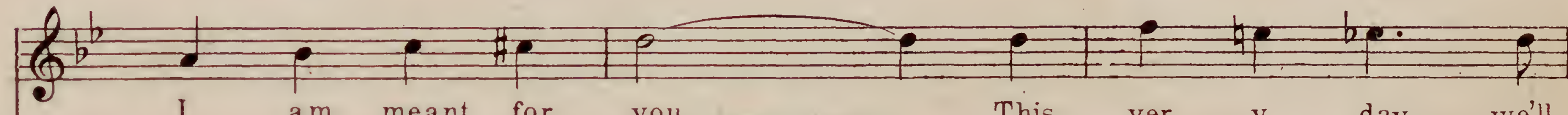

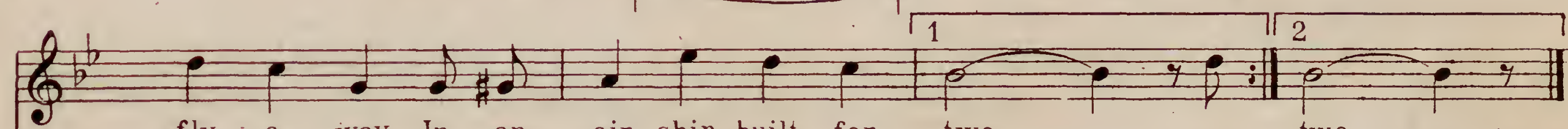
fly a - way In an air ship built for two. two.

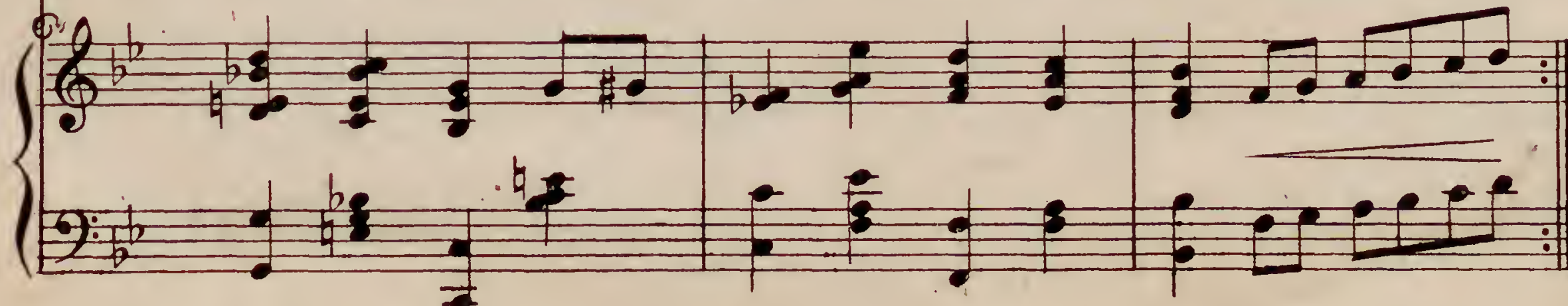
In An Airship Built For Two -2

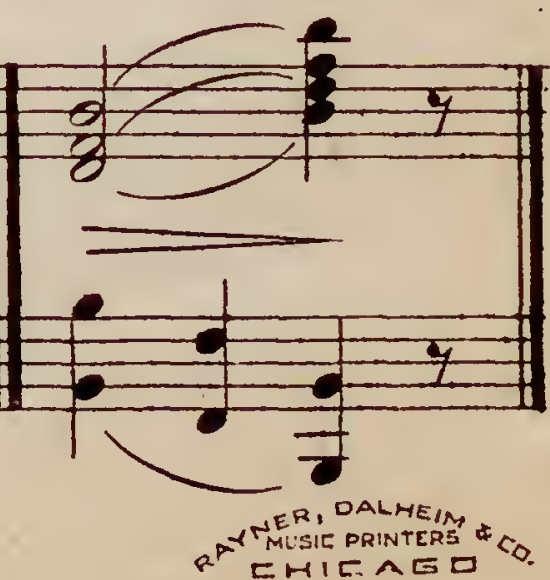




\section{TRY THIS ON YOUR PIANO}

A SONG FULL OF CHARM, BEAUTY AND SYMPATHY

\section{WANT TO GO TO HEAVEN}

For My Mammat Is There Now

Words by PARKFS B.CHURCHILI

Music by JOF.. KINL

CHORUS Tempo di Valse

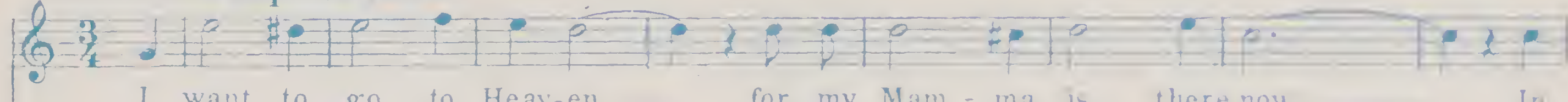

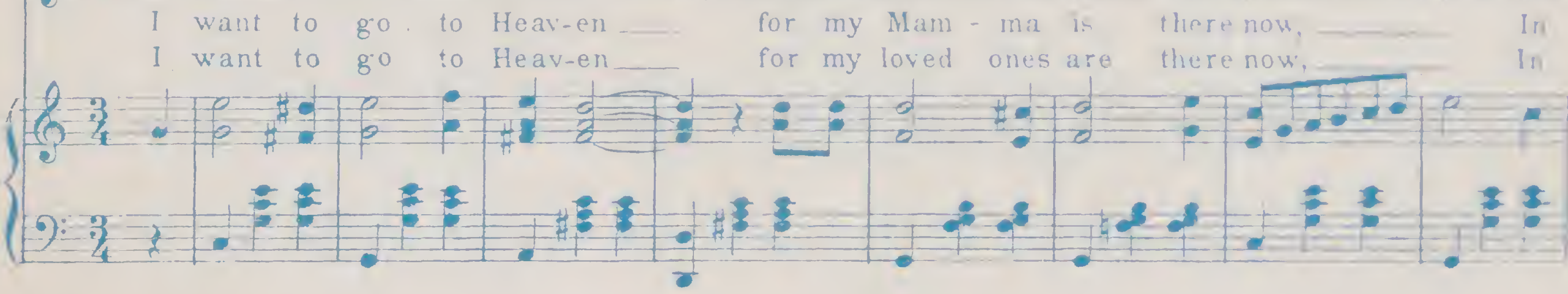

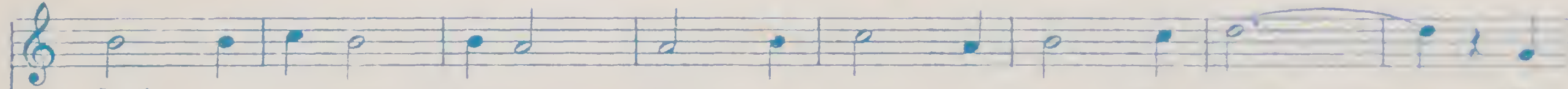

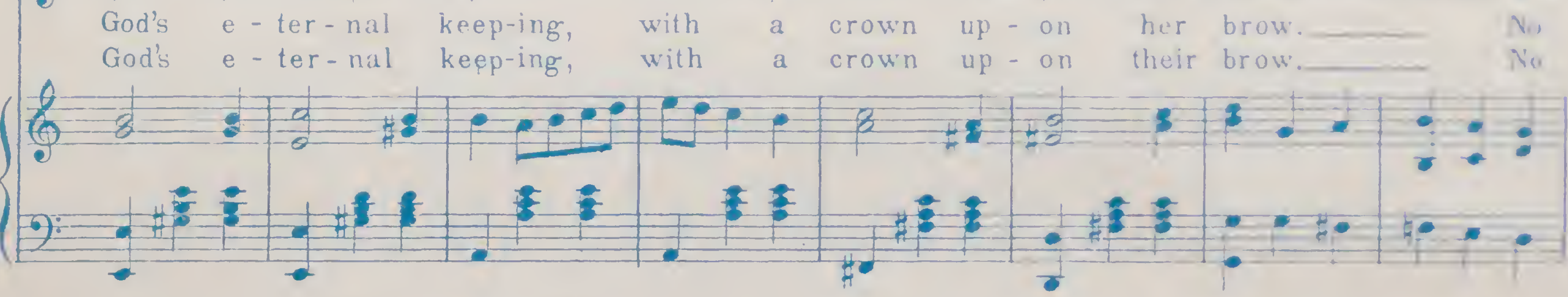

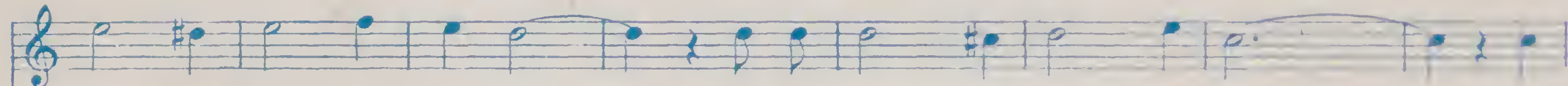

weep - ing and no part-ing_ in that land so bright and fair,

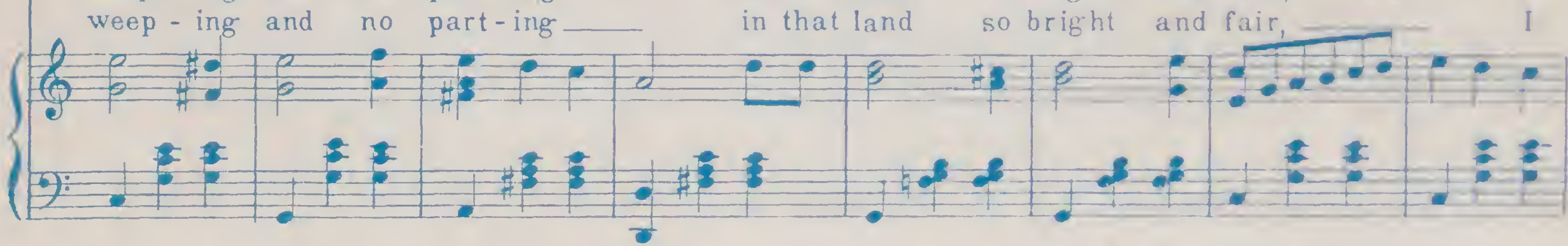
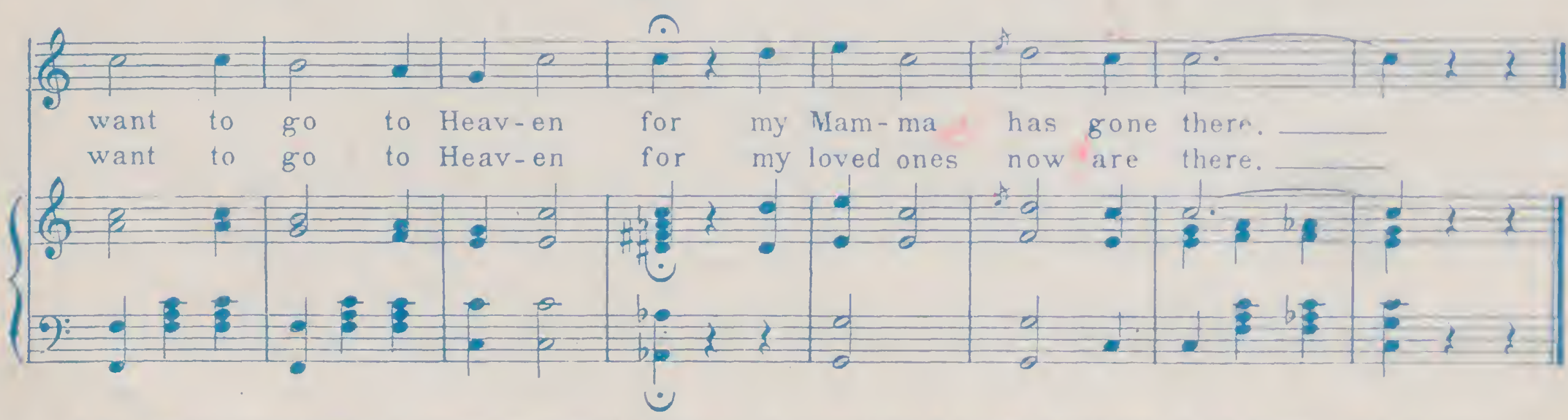

Ask your Dealer to get you this Song or send 15c.to the Publisher for each copy postpaid. P. B. Churchill Music Publisher Trinidad Col. 